\title{
IAMJ
}

INTERNATIONAL

AYURVEDIC

MEDICAL JOURNAL

ISSN: 2320-5091

Impact Factor: 6.719

\section{MISUSE OF TOPICAL STEROID AN ALARMING PROBLEM IN DERMATOPHYTOSIS}

\author{
Lokhande Pooja $\mathrm{A}^{1}$, Sathe Aparna $\mathrm{N}^{2}$ \\ ${ }^{1} \mathrm{PG}$ (scholar) Kayachikitsa department YMT Ayurvedic Medical College and Hospital Kharghar, Maharashtra \\ India \\ ${ }^{2}$ Guided by Associate Professor M.D. Kayachikitsa YMT Ayurvedic medical college and hospital Kharghar, \\ Maharashtra India
}

Corresponding Author: poojalokhande710@gmail.com

\section{https://doi.org/ $10.46607 /$ iamj0608122020}

(Published online: December 2020)

Open Access

(C) International Ayurvedic Medical Journal, India 2020

Article Received: 12/11/2020 - Peer Reviewed: 16/11/2020 - Accepted for Publication: 20/11/2020

(A) Check for updates

\section{ABSTRACT}

Dermatophytoses, commonly known as ringworm or tinea, represent superficial fungal infections caused by dermatophytes, which are among the most common infections encountered in medicine. Recently, there has been tremendous increase in the incidence of dermatophytosis and also patients don't respond to the antifungal therapy. Aim - To probe the probable reason for ineffectiveness of subsequent treatment in management of Dadru after pre-use of topical steroid application. Objective - To compare the clinical and mycological cure in participants with or without use of topical steroidal application before participation in clinical trial. Method - An Experimental comparative clinical trial of 6 weeks duration was done in 50 patients with dermatophytic fungal infections, diagnosed clinically with history of using some form of steroidal application. Result - Out of 50 patients $30(60 \%)$ patients shown complete cure 20(40\%) patients shown ineffectiveness of the treatment, out of 20 patients (75\%) patients had history of steroidal use. Conclusion - Misuse of the steroidal formulation in dermatophytic infection may result in ineffectiveness of the treatment.

Keywords: Dadru, Dematophytes, Chakramarda Beej Churna, Steroid. 


\section{INTRODUCTION}

Dermatophytosis has become a significant health problem in children, adolescents and adults worldwide. In India 5 out of 1000 people suffers from Tinea infection ${ }^{1}$. According to the site of affection dematophytosis is categorized as tinea corporis, Tinea Cruris, Tinea pedis, Tinea barbae. In tinea corporis and cruris it shows a ring of active margin made up of erythmatous papules, tiny vesicles and pustules around a scaly variably pigmented patch. Lesions resolve centrally and progress peripherally to produce the ring like configuration hence name as Ringworm. Tinea corporis indicates the affection of waistline, axillae, buttocks, other parts of trunk and extremities excluding palms and soles. Dermatophytic infection of the groin is called Tinea cruris. Predominantly seen in males on the genitocrural area and the middle aspect of the thighs. Varied skin disarrays are divulged in extensive caption of Kushta in Ayurveda which is further stratified into Mahakushta and Kshudrakushta. Dadru is one amongst Kshudrakushta which has conspicuous analogy with Tinea. While doing the Experimental clinical trial on tinea it was noticed that after taking proper treatment some patients shown the complete clinical and mycological cure but some patients shown the ineffectiveness of the treatment, that's why, choose this topic to probe the probable reason for ineffectiveness of the treatment in management of Tinea.

Aim and Objectives: To probe the probable reason for ineffectiveness of subsequent treatment in management of Dadru after pre-use of topical steroid application.

\section{Objectives:}

1. To compare the clinical cure rate in participants with and without use of topical steroidal application before participation in clinical trial ( $\mathrm{H} / \mathrm{O}$ using steroidal base ointment earlier in disease course).

2. To compare the mycological cure rate in participants with and without use of topical steroidal application before participation in clinical trial (H/O using steroidal base ointment earlier in disease course).
Materials and Methods: Materials taken for the study was for control group terbinafine internal and external for local application, for trial group Chakramarda Beej Churna internal and external for local application. It was prepared in Rasashala of Y.M.T. Ayurvedic College and hospital.

Sampling: 50 participants with confirmed diagnosis of Dadru were chosen randomly from Outdoor patient Department (OPD) of Y.M.T. Ayurvedic Medical College and Hospital, Khraghar, Navi Mumbai.

Ethical Clearance: Institutional Ethic committee (IEC) approval was obtained and written consent was taken from the participants prior to the initiation of the study.

Research Design: Single blind experimental clinical study.

Diagnostic Criteria: Positive $\mathrm{KOH}$ test and typical elevated round skin lesions with allied symptoms.

\section{Inclusion Criteria:}

1. Subjects of either Gender.

2. Subjects more than $18 \mathrm{yrs}$ of age

3. Subject presenting either any or all classical sign and symptoms of Dadru like Itching (Kandu), Erythma (Raga), Papules (Pidika), Dryness (Rukshata).

\section{Exclusion Criteria:}

1. Subjects having any acute systemic illness, uncontrolled DM, $(\mathrm{HbA} 1 \mathrm{c}>7.5)$ etc.

2. Subject having a skin disorder other than Dadru.

3. $\mathrm{K} / \mathrm{C} / \mathrm{O}$ Immuno compromising conditions or on immunosuppressive drugs.

4. Pregnant and lactating mothers.

\section{Criteria for Assessment:}

\section{Objective Criteria:}

A. Mycological cure (KOH Test).

B. Photographs.

The laboratory $\mathrm{KOH}$ Preparation and photographs were considered at the initiation, completion of treatment period $\&$ at the end of the trial.

\section{Subjective Criteria - Table No. 1}

Selection of drug or medicines -Properties of Drug placed in table no. 2 
Drug, dosage and duration: Posology is mentioned at table no. 2

Observation: In the present study, a total number of 50 participants were registered, and all patients completed the treatment. Out of 50 patients, $30(60 \%)$ patients showed complete cure, 20(40\%) patients showed ineffectiveness of the treatment in all parameter of assessment, also observed that out of 20 patients 15 patients had history of use of steroid.

\section{Results}

Effect on clinical symptoms:

1. Itching (Kandu): Out of 50 patients $32(64 \%)$ patients showed complete cure and 18 (36\%) patients didn't showed the complete cure. Out of 18 patients $15(83 \%)$ patients had history of steroidal use.

2. Papules (Pidika): Out of 50 patients 35 (70\%) patients showed the complete cure after treatment, $15(30 \%)$ patients showed the ineffectiveness of the treatment, out of 15 patients $12(80 \%)$ patients had history of steroidal use.

3. Erythma (Raga): Out of 50 patients $36(72 \%)$ patients showed the effectiveness of the treatment but $14(28 \%)$ patients showed ineffectiveness of the treatment. Out of 14 patients $10(71 \%)$ patients had the history of the steroidal use.

4. Dryness (Kandu): Out of 50 patients 46 (92\%) patients showed the complete cure after the treatment but $4(8 \%)$ patients showed the ineffectiveness in the treatment, and that all $4(100 \%)$ patients had history of steroidal use.

\section{KOH test}

In parlance with diagnostic criteria all the patients were $\mathrm{KOH}$ positive when enrolled for the study. Subsequent after the period of 4 week 35 (70\%) patients turned out $\mathrm{KOH}$ negative. In history they did not reveal use of steroidal application earlier in their disease course. Remaining 15 (30\%) participant were persistent $\mathrm{KOH}$ positive status after completion of 4week treatment. When they were exploring for the probable reason for the ineffectiveness of the treatment it was found that out of 15 participant 12 $(80 \%)$ participant gave positive history of steroidal base application. Further it was observed that in treatment free observation of 2 week among 35 improved participant 5(14\%) of participant showed recurrence. All the participants with recurrence were from control group. Probable cause of this relapse could be resistance to the terbinafine molecule. For affirmation there is need of further scrutinization of the fact with trial in large scale.

\section{DISCUSSION}

Tinea an acute or chronic infection occurring throughout the world is more prevalent in tropical areas owing to temperature and humidity. In the present study the desired effect of the treatment not observed in few cases after taking proper history it was observed that these participants had history of steroidal use, they had applied counter creams or ointments containing corticosteroids to their rash earlier in their disease course. Steroidal cream can be helpful for some skin problems and can even temporarily reduced Tinea symptoms like Itching, Redness but they don't kill fungus that causes Tinea. In few cases steroidal creams allow the fungus that causes Tinea to invade deeper into the skin and causes a more serious condition. In such cases it is also observed that there happens the change in the appearance of the lesions such as doubling of edges, multiple rings, and extensive spread covering more of the body parts thickening of skin, formation of striae and pigmentary changes. This could be contributed to high potency corticosteroidal application at sensitive skin region or excessive use of $\mathrm{it}^{2-3}$. In present study the hypertrophy of the skin would have been leading to the main disadvantage for trans-dermal drug delivery. Poor penetration owing to hypertrophy could be accountable cause for the treatment failure.

\section{CONCLUSION}

In this study sincere attempt has been made to draw definite conclusion regarding the probable reason for ineffectiveness of the treatment in management of the Dadru. The study can be concluded as follow the participants who did not have any history of steroidal 
use shown the complete clinical and mycological cure. Those who had the history of steroidal application didn't shown the desirable effect of the treatment and there was further exacerbation of the lesion. Literature review also mentioned about atypical manifestation of the disease with less Erythma, decreased scaling and indistinct border post steroidal base application. Though this finding is not observed in present study its worth mentioning here in this context. Steroid base application probably leads to dermatophyte invasion deeper in skin layer. It can invade deeper than the epidermis (into dermis and subcutaneous tissue) which further makes the treatment ineffective. Thus, misuse of the steroids may lead to ineffectiveness of the treatment.

\section{REFERENCES}

1. WHO 2005, Epidemiology and management of common skin disease in children in developing country WHO/FCH/CAH 05.12

2. Arenas R, Moreno-Coutiño G, Vera L, Welsh O. Tinea incognito. external icon Clinics in Dermatology. 2010 March.

3. Wacker J, Durani BK, Hartschuh W. Bizarre annular lesion emerging as tinea incognito. external icon 2004 Oct 22.

4. Verma S. Emergence of recalcitrant dermatophytosis in India external icon. Lancet Infect Dis. 2018 July 1.

Table 1

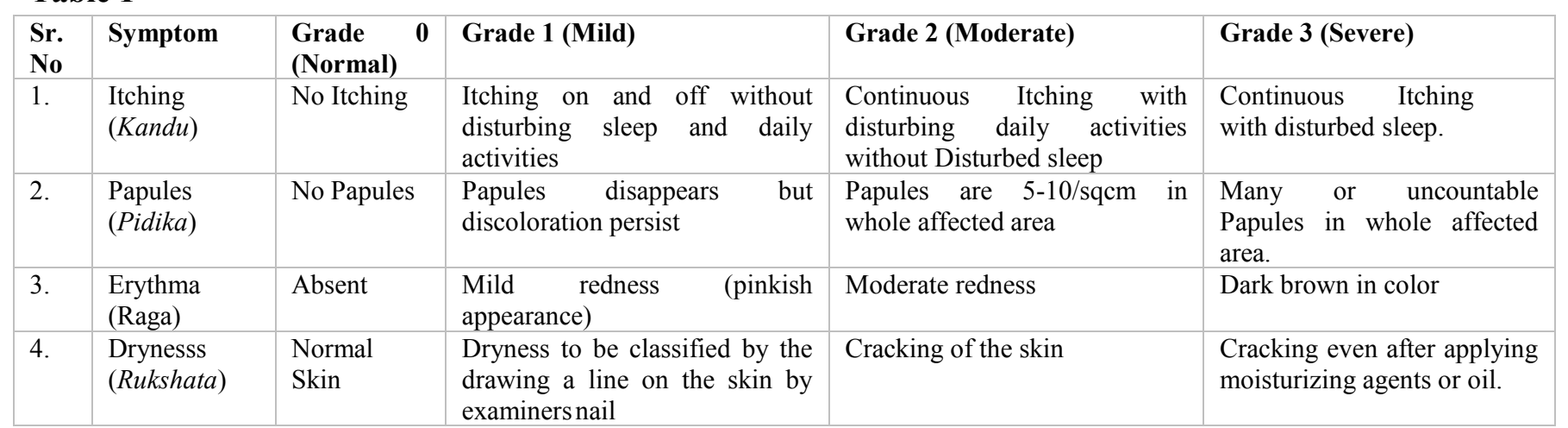

Table 2

\begin{tabular}{|l|l|l|}
\hline $\begin{array}{l}\text { Name of the } \\
\text { drug }\end{array}$ & $\begin{array}{l}\text { Group A } \\
\text { Chakramarda beej churna } \\
\text { L.N. - Cassia torra } \\
\text { Prayojya ang- beej }\end{array}$ & Terbinafine \\
\hline $\begin{array}{l}\text { Duration of } \\
\text { the therapy }\end{array}$ & $\begin{array}{l}\text { Treatment duration - 4-week treatment period Drug free } \\
\text { observation - weekly for two weeks after cessation of } \\
\text { treatment. }\end{array}$ & $\begin{array}{l}\text { Treatment duration- 4 week treatment period. Drug free } \\
\text { observation - weekly for two weeks after cessation of } \\
\text { treatment. }\end{array}$ \\
\hline Dose & $\begin{array}{l}\text { 2gmeng once in a day with Lukewarm orally and locally 1\% ointment } \\
\text { mixed with lukewarm water for local application }\end{array}$ \\
\hline Time & $\begin{array}{l}\text { Luke in a day } \\
\text { Terbina 1\%) }\end{array}$ & once in a day \\
\hline Anupana & weekly for 6 weeks & - \\
\hline Follow up & Laghu supachcha ahar. & weekly for 6 weeks \\
\hline Diet & & - \\
\hline
\end{tabular}

\section{Source of Support: Nil \\ Conflict of Interest: None Declared}

How to cite this URL: Lokhande Pooja A \& Sathe Aparna N: Misuse Of Topical Steroid An Alarming Problem In Dermatophytosis. International Ayurvedic Medical Journal \{online\} 2020 \{cited December, 2020\} Available from: http://www.iamj.in/posts/images/upload/5242 5245.pdf 